\title{
CORRESPONDENCE
}

\author{
Breast cancer: a case for conservation \\ Sir Reginald Murley, Frcs........... 984 \\ Cancer of the cervix and screening \\ Dayantha S Fernando, MRCGP.......... 985 \\ Non-smoking wives of heavy smokers \\ have a higher risk of lung cancer \\ G H Miller, PHD; M Rutsch, MD . . . . . . . 985 \\ Levodopa: long-term impact on \\ Parkinson's disease \\ D M A Mann, PHD, and P O Yates, FRCPATH 985 \\ Prognosis of patients with "chest pain \\ ?cause" \\ D J Maberly, FRACP; J A C Thorpe, FRCS; \\ P Bechgaard, MD; R T D FitzGerald, MB . . 986 \\ Chest pain and cardiac arrest \\ P G P Lawler, Ffarcs; J M Rawles, MRCP \\ and others; A D Redmond, MD......... 987 \\ The pacing industry \\ D B Shaw, MD. . \\ Legionella pneumophila and water \\ systems \\ H Gordon, MFCM; R J Fallon, FRCPATH. . . 988 \\ $A$ question of life and death \\ Jane Riley, BSC; R M McFadzean, FRCSED. . 988 \\ Drug prevention of malaria \\ A W Woodruff, FRCP, and others; G Y \\ Caldwell, MB.................. 988 \\ Group $R$ streptococcal infection \\ M R Clements, MRCP, and D V Hamilton, \\ MRCP ................... 989 \\ Recurrent renal calculi \\ W Brumfitt, FRCPATH, and others. . . . . . . 989 \\ Haemophilus influenzae endophthalmitis \\ K R F Boomla, MRCP, and R P Quilliam, \\ MRCP ..................... 989 \\ Statistics and ethics in medical research \\ J Dobbing, FRCPATH; D G Altman, BSC. . . 990 \\ Impaired glucose tolerance and \\ diabetes-WHO criteria
}

R J Jarrett, MD . . . . . . . . . . . . . 990
Facial palsy

B W Lewis, MRCP; R S Trompeter, MRCP. . 990

Secretory otitis media and grommets

P K Schutte, MRCGP. . . . . . . . . . . 991

Effect of a low pertussis vaccination uptake on a large community

J Wilson, FRCP. . . . . . . . . . . . 991

Status epilepticus treated by barbiturate anaesthesia

A W Logie, MRCP, and Pamela S Christian

MSC..................... 99

Urban hypothermia

P J Bickford Smith, FFarcs; R Bowesman,

MD ...................... 991

Echoes from the gall bladder

J Jones, MrCP . . . . . . . . . . . . . . . 992

A trial speech screening test for school

entrants

E F Flint, FRCs; M J Rigby, BA, and Irene

L Chesham, FFCM. . . . . . . . . . . . . 992

Psoriasis and its treatment

R H Seville, FRCP, and G B Walker, MB . . . 992

Left hand, right hand

M D Kopelman, MB; A A Beaton, PHD . . . . 992

Hunting rare adverse drug reactions

C R Martys, MD................. 993

Do fetal movements reflect fetal

wellbeing?

D D Mathews, FRCOG ; Kathryn A Rosenberg,

PHD, and F A Boddy, FFCM........... 993

"Rocking the Cradle"

R G D Newill, MD . . . . . . . . . . . . . . . 993

Unquiet sleep

L M Franklin, MRCPSYCH . . . . . . . . . . . 994

Five years in Bogalusa

Cicely D Williams, FRCP............. 994

They are still with us

A J Duggan, FRCP............. 994
"British National Formulary"

H K Ford, FRCGP; C M Miller, FRCP.... . . 994

Amniotic fluid phospholipid profile

D K James, MB, and A Harkes. . . . . . . . . . . 994

Female sterilisation-no more tubal coagulation

$M$ H Wilkins, FRCSED, and N V Colley,

MRCs; C Atkins, and H G Meredith..... . . 994

Clouded agarics

C A Birch, FrCP. . . . . . . . . . . . . . . . . 995

Patients in wheelchairs

Maureen A Tudor, MB . . . . . . . . . . . . . 995

Medical responsibilities of airlines

B D Lask, MRCPSYCH . . . . . . . . . . . . 995

Protest against punishment by amputation

J P R McCulloch, MB . . . . . . . . . . . . . 995

Reciprocal treatment for Britons in Greece

S Doxiadis, FRCPED . . . . . . . . . . . . . 995

Spectacle problems

L G Fison, FRCs . . . . . . . . . . . . . . 995

Spectacle frame prices

S W V Davies, MB................... 996

Still no widowers' pensions

Anne L Grüneberg, FFARCs . . . . . . . . . 996

Milage payments for hospital doctors

C K Connolly, frCP. . . . . . . . . . . . 996

Finding a practice-a further caveat

P J Gorrod, ACA . ..................... 996

Acute hospital services in London

K A M Grant, мFCM. . . . . . . . . . . . 996

Preregistration posts and cuts

J M Potter, FRCS. . . . . . 997

"Drugs and Therapeutics Bulletin" not

free in Scotland

M G Bamber, MB. . . . . . . . . . . . . . . . 997

Oxfordshire AHA and making ends meet

M H Gough, FRCS................ 997

We may return unduly long letters to the author for shortening so that we can offer readers as wide a selection as possible. We receive so many letters each week that we have to omit some of them. Letters must be signed personally by all their authors. We cannot acknowledge their receipt unless a stamped addressed envelope or an international reply coupon is enclosed.

Correspondents should present their references in the Vancouver style (see examples in these columns). In particular, the names and initials of all authors must be given unless there are more than six, when only the first three should be given, followed by et al; and the first and last page numbers of articles and chapters should be included. Titles of papers are not, however, included in the correspondence section.

\section{Breast cancer: a case for conservation}

SIR,-In your leading article "Breast cancer: a case for conservation" (7 March, p 759) you refer to the pioneer work of Sir Geoffrey Keynes, 1 to whom the greatest credit should be given for encouraging some surgeons to look more critically at their results. Alas, in the 54 years since the publication of that report many have shown a curious reluctance to face the facts.

One of your predecessors was kind enough to publish a detailed review of conservative and radical surgery which three of us prepared in 1953.2 That series was of considerable interest because it included all of Keynes's cases at St Bartholomew's Hospital in the decade 1930-9. Working on that study with a skilled radiotherapist and an excellent statistician, I personally learnt that, in terms of survival, there seemed little to choose between different methods of treatment. Our group was impressed by the failure to improve survival and also by the increased morbidity of more radical methods. Indeed, there was some evidence that survival might be prejudiced, though this was not statistically significant.

Our survey showed that simple surgery carried a higher incidence of local recurrence, though in 127 of 216 cases the primary operation had consisted of no more than a local excision. Notwithstanding increased local recurrence, it was clear that limited surgery did not prejudice survival; but 10 of the 127 patients having local excisions subsequently had more extensive surgery.

It is now fashionable to advocate prospective randomised trials, though many fail to realise how difficult the conduct of such trials can be.
They become more difficult in the context of fully informed consent as this is now understood and acted on by the enlightened doctor. Moreover, many of the randomised trials in breast cancer have done no more than confirm what some of us previously learnt from scrupulously planned retrospective studies. I have no wish to seem scornful of the randomised prospective trial, but I do submit that far too many doctors have become obsessed with the concept without realising the snags when it comes to the management of intelligent and properly informed patients.

My personal participation in the Barts research has had a profound effect on my practice in the ensuing 28 years. I gave up radical surgery while the research was in progress and have never regretted that decision. For some years simple mastectomy with 
limited axillary dissection and postoperative irradiation was my usual practice. But I gradually became more sceptical and unhappy about routine irradiation even after simple mastectomy. Ralston Paterson ${ }^{3}$ clearly showed that routine irradiation added nothing useful to the radical operation, while Bond ${ }^{4}$ and others showed that either axillary dissection or routine irradiation for node-negative cases was prejudicial to survival. Since Paterson and Bond's work seemed only to confirm my own experience I came to simplify the management of my patients still further. Moreover, because of my experience in the follow-up of Keynes's cases I became more and more ready to undertake local excision and other alternatives. At first such patients were those who refused mastectomy; but, in the course of time, I was prepared to offer local excision as an alternative to mastectomy in other patients too. These were principally those with a tumour situated at the periphery of the breast or where there was a relatively small tumour in a relatively large breast. A number of these women did not receive supplementary irradiation and these included some nurses and doctors.

Thirty-five years' experience in two busy regional hospitals and the strictly personal follow-up of all my cases have convinced me that I have a clear duty to explain to many patients that there is no reason why their personal predilections should not be a most important determinant in treatment. Despite wartime experience in plastic surgery I have not made use of prosthetic inserts, either at the time of operation or later; but I accept the logic of their use by experienced surgeons in the treatment of suitably selected and informed patients. ${ }^{5} 6$

The penultimate paragraph of your editorial refers to a "tightly randomised study" to prove that conservative surgery plus radiotherapy would produce comparable results to "conventional treatment." But what do you mean by conventional? Analysis of the practice of 600 fellows of the Association of Surgeons of Great Britain and Ireland by Forrest ${ }^{4}$ showed wide variation in the surgical and supplementary treatment of breast cancer.

I believe that surgeons in general will do more good for more women by being prepared to offer methods of treatment adapted to individual circumstance and choice. And, if these patients were always given the fullest information about such facts as already are known to us, I think that it would become increasingly difficult to mount a valid and ethical randomised prospective study. Would it not be far wiser, therefore, to concentrate on carefully co-ordinated retrospective studies? These might well command the support of much larger numbers of doctors and patient and also more quickly persuade others of Keynes's wisdom.

London W1N 1DF

Reginald MURLeY

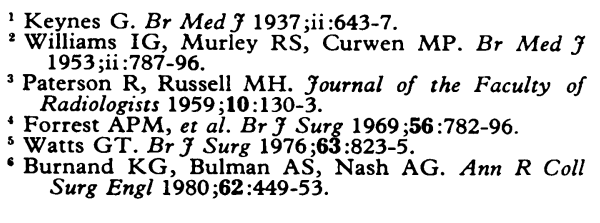

\section{Cancer of the cervix and screening}

SIR,-As a general practitioner, I take exception to Dr J Elizabeth Macgregor's suggestion (28 February, p 734) that our maternity fees should be withheld until a satisfactory smear has been taken. The days when GPs were patronised from ivory towers in this fashion ended a long time ago.

There is a widely held opinion that a woman should have a cervical smear reasonably soon after commencing sexual activity and, if this is normal, every three years thereafter. The present system allows a GP to be paid only once every five years after the age of 35 unless the patient has had three pregnancies. The real villains therefore are the DHSS and our own negotiators for allowing this iniquitous system of fees to continue.

As for Dr Macgregor's second brainwave, about holding up maternity grants, I suggest that she writes to the national press in order to sample the opinion of the general public.

Camberley, Surrey GU15 2NN

D FERNANDO

\section{Non-smoking wives of heavy smokers} have a higher risk of lung cancer

SIR,-It is interesting to note that Dr Takeshi Hirayama's study on non-smoking wives of heavy smokers (17 January, p 183) showed an impact on mortality similar to that recorded by the Pennsylvania study on passive smoking.

Both studies are similar in design since the non-smoking wives were separated into two different categories based on the smoking habits of their husbands. The Hirayama study showed an approximate one-third increase in mortality rate for non-smoking women whose husbands smoked compared with non-smoking women whose husbands did not smoke. The findings from the Pennsylvania study on passive smoking, which considered longevity based on all causes of death, showed a fouryear longevity curtailment for non-smoking wives whose husbands smoked compared with non-smoking wives whose husbands did not smoke. This four-year difference was approximately one-quarter of the total longevity difference between smoking women and nonsmoking women reported in the Northwestern Pennsylvania study on smoking and health. ${ }^{2}$ Thus Hirayama's new study gives additional evidence of the deadly impact of passive smoking on the non-smoker.

G H MILLER

Edinboro, Pennsylvania 16412,

Miller GH. Fournal of Breathing 1978;41(5):5-9. 2 Miller GH. Journal of Breathing 1976;39(19):1-12.

SIR,-Dr Takeshi Hirayama (17 January, $p$ 183) asserts that non-smoking Japanese women married to husbands who smoke have an increased risk of lung cancer and interprets his findings as a consequence of passive smoking. We have taken a closer look at his results and have come across some apparent inconsistencies, especially concerning the lung cancer deaths within the subpopulation of unmarried women and the alleged difference between urban and rural populations.

From Hirayama's figures we can calculate that 101 lung cancer deaths occurred in a group of 33951 unmarried women. Assuming both the proportion of smokers and the proportion of lung cancer deaths among smokers to be the same in unmarried women as in married women, we can calculate a crude lung cancer death rate for unmarried non- smoking women of $18 \cdot 0 / 100000$. This group is not exposed to passive smoking as specified by Dr Hirayama, and yet the crude death rate is not only more than that of non-smoking wives of non-smokers $(10 \cdot 4 / 100000)$ but also higher than that of non-smoking wives of smokers (14.6/100 000). One may argue that the unmarried women were in fact likely to have smoked more than the married women. However, it can be shown that it would require there to be more than $50 \%$ smokers among unmarried women to explain their excess crude lung cancer death rate over that of married women, and this seems unlikely for Japanese women over 40 years old at the time of enrolment.

Hirayama's assertion that the risk associated with passive smoking is particularly marked in wives of young agricultural workers does not appear to be supported by the data he presents in table II. He gave observed numbers of lung cancer deaths of three, 20 , and 16 respectively, for wives of nonsmokers, of ex-smokers or 1-19 cigarettes/day smokers, and of smokers of more than 20 cigarettes/day. Had the relative lung cancer rates by smoking habits been those found for all young women, the corresponding expected numbers of deaths would have been $5 \cdot 36$, $19 \cdot 00$, and 14.64 , figures which do not differ significantly from those observed $\left(\chi^{2}=2 \cdot 34\right.$, 2 df). Thus the rather "post hoc" theory suggested by Dr Hirayama to explain what he sees as a very marked effect of passive smoking in rural areas is not required. In any case, it seems daring to assert a sharp increase in mortality on the basis of only three lung cancer deaths in the critical non-exposed group, bearing in mind the unreliability of cause of death indicated on death certificates.

In the presence of the discrepancies in Dr Hirayama's paper as pointed out above, we think it problematic to relate the higher risk for lung cancer in non-smoking women married to smokers to passive smoking. In our opinion other factors, not considered by Hirayama, might be responsible for the different lung cancer mortalities.

\section{MaRTin RUTSCH}

Institut für Statistik und Mathematische Wirtschaftstheorie,
Karlsruhe, West Germany

\section{Levodopa: long-term impact on}

\section{Parkinson's disease}

SIR,-The leading article in the $B M \mathcal{F}$ of 7 February ( $p$ 417) again highlights the problems of levodopa treatment of Parkinson's disease. The majority of patients with this disorder show marked improvements on commencement of levodopa; yet many have dropped out within two years, and after six years only about a quarter still receive some benefit. ${ }^{1}$ Psychiatric complications are often the reason for cessation, though in many cases it seems that there is simply a "wearing off" of effect. Although it has been suggested ${ }^{2}$ that deterioration of response may result in some way from levodopa itself, the pathological cause is not understood.

Cells of the substantia nigra are rather unusual in as much as they contain neuromelanin and not the familiar age pigment lipofuscin. Dopamine, the neurotransmitter agent, is not only catabolised enzymatically but also auto-oxidises into quinones, which are subsequently incorporated into the melanin granule. ${ }^{3}$ Essentially neuromelanin is a "melanised" lipofuscin and is accumulated within 